\title{
Influence of front slope gradient and the angle between tunnel and slope on stability of tunnel portal
}

\author{
Huaan $\mathrm{Wu}^{1}$ and Huahui $\mathrm{Jin}^{2 *}$ \\ ${ }^{1}$ Yuhuan Agriculture Rural Affairs and Water Conservancy Bureau, Yuhuan 317602, China \\ 2 Zhejiang Guangchuan Engineering Consulting Co, Hangzhou 310020, China
}

\begin{abstract}
Shallow buried and unsymmetrically loaded tunnel is the most common type of mountain tunnel portal. Currently, most of the studies mainly focus on the stability of side slope, while the investigation on the deformation of the front slope after tunnel excavation is relatively less. In this paper, the influence of front slope gradient and the angle between tunnel and slope on stability of tunnel portal was analyzed by $F L A C^{3 \mathrm{D}}$. The results show that: When the front slope angle is greater than $40^{\circ}$, the slope deformation caused by tunnel excavation is larger with the increase of slope angle. In order to ensure the safety of construction, we should not only pay attention to the treatment of the front slope before the tunnel excavation, but also pay attention to the monitoring of the front slope deformation during the excavation of the tunnel portal section. And the most suitable entry angle between tunnel axis and the front slope is $0^{\circ}$, which can control the vertical displacement of relatively large deformation. The research conclusions can provide some reference for the excavation and support design of mountain tunnel portal.
\end{abstract}

\section{Introduction}

In the construction of highway in mountainous areas, tunnel is often the largest investment project, but also the control project ${ }^{1,2}$. In the process of tunnel construction, the stability of the portal slope is often in a prominent position.

Currently, the research on slope instability mainly focuses on the deformation of slope caused by surface excavation and filling ${ }^{3,4}$, redistribution of stress field ${ }^{5}$ and displacement field ${ }^{6,7}$. The influence of tunnel excavation on slope stability was mainly concentrated on the side slope of unsymmetrically loaded tunnel ${ }^{8,9}$, but the research on the deformation of the front slope is still not enough. In fact, many failures such as cracking and instability and collapse of the front slope occurred in the process of tunnel portal excavation. Such as the Chejiaoshan tunnel in Jinan City, Shandong Province, China, large cracks appeared in the process of entering the tunnel ${ }^{10}$. During the excavation of Hekou tunnel (Lanzhou City, Gansu Province, China), a large number of cracks appeared on the front slope. And there were signs of further sliding and collapse ${ }^{11}$. The main reason was that the influence of portal excavation on the deformation of the front slope is ignored.

Therefore, it is necessary to study the influence of excavation at the entrance of mountain tunnel on the deformation law of the front slope. In this paper, 3D numerical calculation is been used to analysis the deformation of the slope under different slope gradient and the relationship between the slope and the tunnel axis. The conclusions can provide some reference for the stability design of the slope at the entrance of mountain tunnel.

\section{Influence of front slope gradient}

\subsection{3-D model and calculation parameters}

According to the characteristics of mountain tunnel portal, the established three-dimensional numerical model is shown in Fig. 1. Four different front slope gradients $\alpha$ are considered, i.e. $\alpha=30^{\circ}, 40^{\circ}, 45^{\circ}$ and $50^{\circ}$. In the $x$ direction, the right boundary of the model was taken to the natural surface, and the left boundary was taken to 5 times the excavation span of the tunnel. In the $y$ direction, the upper boundary was taken to the natural surface, and the bottom was taken as 4 times the excavation height of the tunnel. In $z$ direction, the length is $80 \mathrm{~m}$, and the buried depth of the tunnel was $3 \mathrm{~m}$ at the boundary of $z=0$. There were about 20494 grid points and 57292 zones of the model.

In the calculation, the upper and right boundaries were free boundaries, and the other boundaries were constrained by normal displacement. Considering that the surrounding rock at the tunnel entrance is seriously weathered and very broken, it was calculated as grade $\mathrm{V}$ surrounding rock according to Chinese code. The surrounding rock was elastic-plastic material, the yield criterion was $\mathrm{M}-\mathrm{C}$ criterion, and the initial support was elastic model. The self-weight load was considered in the initial load, and the material parameters used in the calculation are shown in Table 1.

\footnotetext{
* Corresponding author: 691436049@qq.com
} 
Table 1. Parameters of surrounding rock and initial support.

\begin{tabular}{|c|c|c|}
\hline Parameters & Surrounding rock & Initial support \\
\hline Gravity $\left(\mathrm{kN} / \mathrm{m}^{3}\right)$ & 20 & 22 \\
\hline $\begin{array}{c}\text { Elasticity modulus } \\
(\mathrm{GPa})\end{array}$ & 1.5 & 21 \\
\hline Poisson's ratio & 0.33 & 0.2 \\
\hline Cohesion (MPa) & 0.4 & - \\
\hline Internal friction angle $\left(^{\circ}\right)$ & 24 & - \\
\hline
\end{tabular}

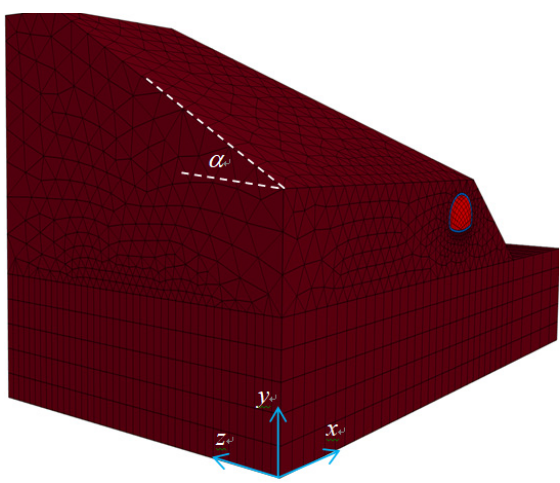

Fig. 1. Three-dimensional model.

\subsection{Calculation results}

Fig. 2 shows the vertical displacement and horizontal displacement of the slope along the axis of the tunnel $(z$ direction). The vertical displacement increases with the increase of $z$, while the horizontal displacement decreases with the increase of $z$. This is consistent with the arc shear slip mode: the horizontal displacement is small because the back of the slope sinks and slides in an arc, while front of slope tilts up and shears out, so the horizontal displacement is increased while the vertical displacement is reduced. The horizontal displacement of the slope is 10 times smaller than the vertical displacement, and the vertical displacement is more affected by the tunnel excavation than the horizontal displacement. It indicates that the displacement of the slope caused by excavation is mainly vertical displacement, and the second is horizontal displacement. When $\alpha$ less than $40^{\circ}$, the vertical displacement and horizontal displacement increase slowly with the increases of $\alpha$; When $\alpha$ is greater than $40^{\circ}$, the vertical displacement and horizontal displacement increase even greater with the increases of $\alpha$. It shows that when $\alpha$ is larger than $40^{\circ}$ The tunnel excavation is easy to cause the slope instability.

Fig. 3 shows the vertical displacement and horizontal displacement of the ground along the $x$ direction in $z=0$ plane after tunnel excavation. The main area affected by tunnel excavation is near the tunnel, and the rocks far away from the tunnel is relatively less affected. The horizontal displacement of the tunnel shows a hump curve with central subsidence, which indicates that the two sides of the tunnel tend to squeeze into the tunnel. The vertical displacement is 10 times higher than the horizontal displacement, which indicates that the failure mode of the slope near the tunnel is "collapse". The larger the $\alpha$ is, the more serious the "collapse" near the tunnel is, and the larger the "collapse" range is. When $\alpha$ is greater than $40^{\circ}$ the scope of influence increases faster.

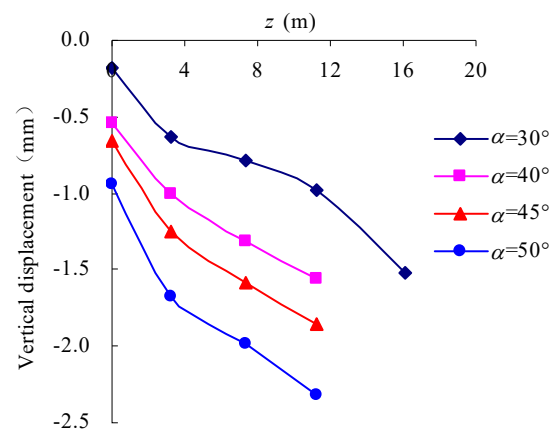

(a) Vertical displacement

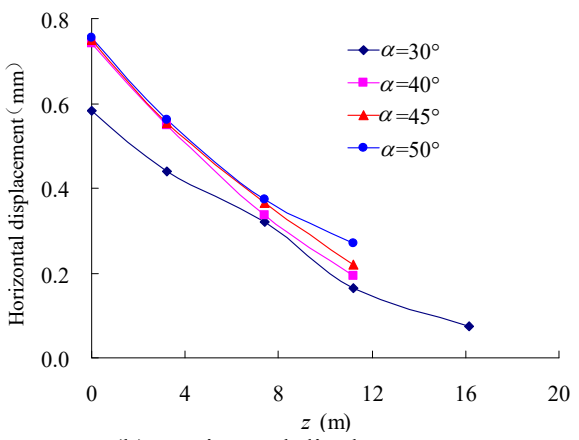

(b) Horizontal displacement

Fig. 2. Displacement of the slope along the axis of the tunnel

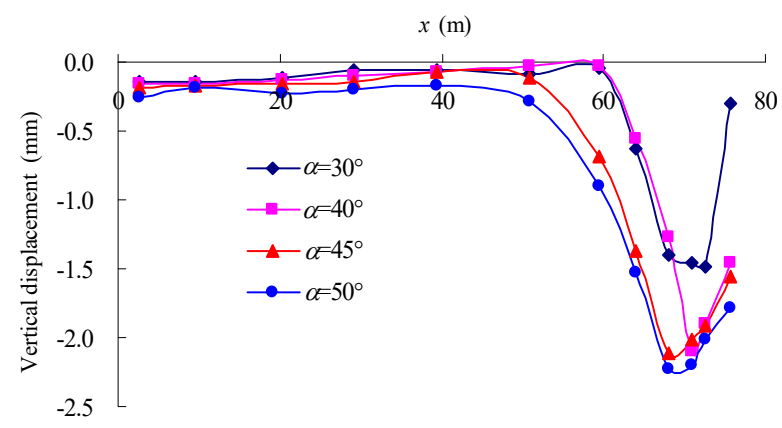

(a) Vertical displacement

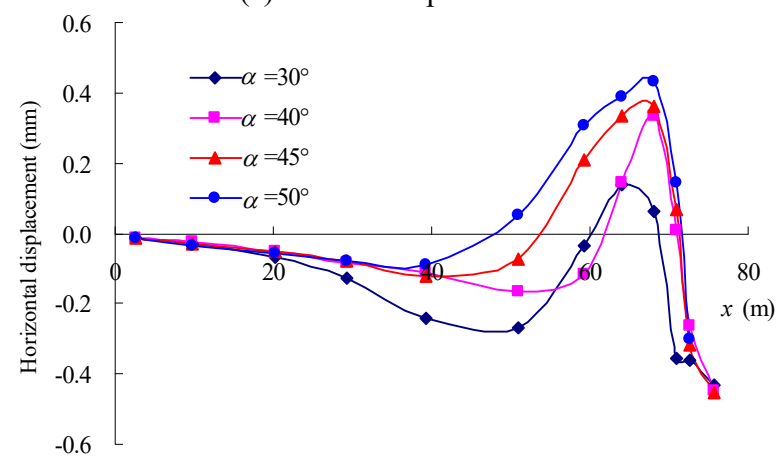

(b) Horizontal displacement

Fig. 3. Displacement of the surface at $z=0$ plane. 


\section{Influence of the angle between tunnel and front slope}

The influence of the intersection angle between the tunnel and the slope, that is, the angle $\beta$ shown in Fig. 4 , $\beta=0^{\circ}, 10^{\circ}, 20^{\circ}, 30^{\circ}$ and $40^{\circ}$. Other dimensions of the numerical model were the same as those in Fig. 1, and the front slope gradient $a=45^{\circ}$ in the calculation.

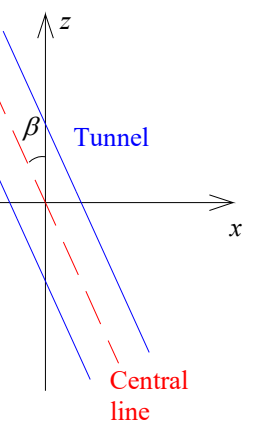

Fig. 4. Angle $\beta$ between tunnel and the slope.

Fig. 5 shows the displacement of the slope at the entrance under different $\beta$. When $\beta$ is less than $30^{\circ}$, the vertical displacement increases with the increase of $\beta$. When $\beta$ is greater than $30^{\circ}$, the vertical displacement decreases with the increase of $\beta$. The horizontal displacement is larger at the front edge and smaller at the back edge of the slope. The larger the $\beta$ is, the greater the influence of tunnel excavation on the horizontal displacement of the back edge of the head slope is.

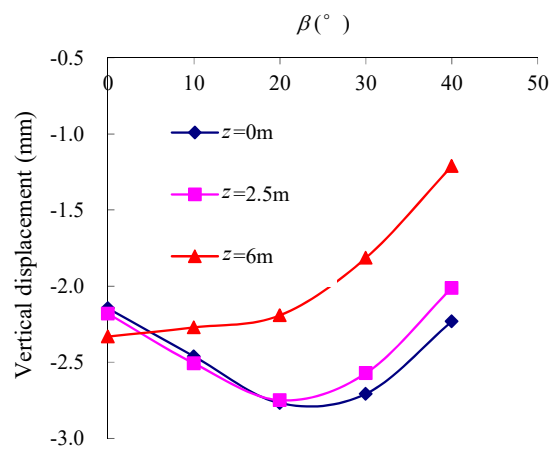

(a) Vertical displacement

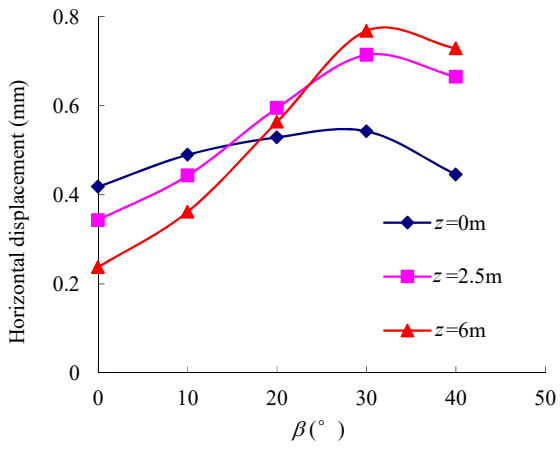

(b) Horizontal displacement

Fig. 5. Displacement of the slope along the axis of the tunnel.
Fig. 6 shows the vertical displacement and horizontal displacement of the ground along the $x$ direction in $z=0$ plane after tunnel excavation. The horizontal displacement shows a hump curve with the middle part sinking, which indicates that there is a tendency of squeezing into the tunnel on both sides of the tunnel. The vertical displacement is 10 times larger than the horizontal displacement, which indicates that the failure mode of the slope near the tunnel is "collapse" mode. The larger the $\beta$ is, the more serious the "collapse" near the tunnel is, and the scope of "collapse" moves to the side of the ridge.

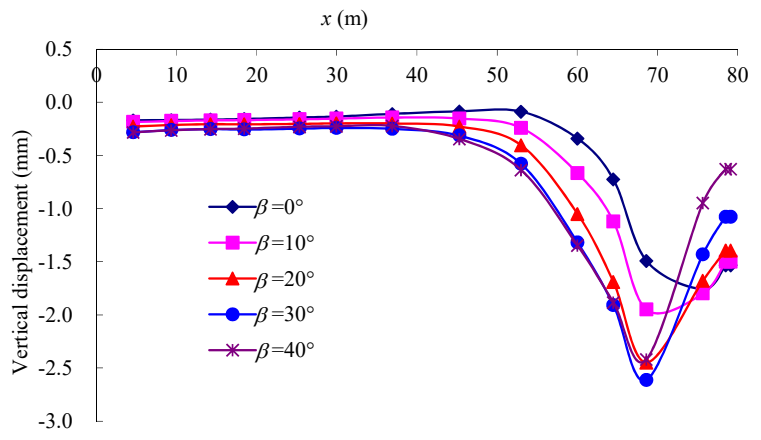

(a) Vertical displacement

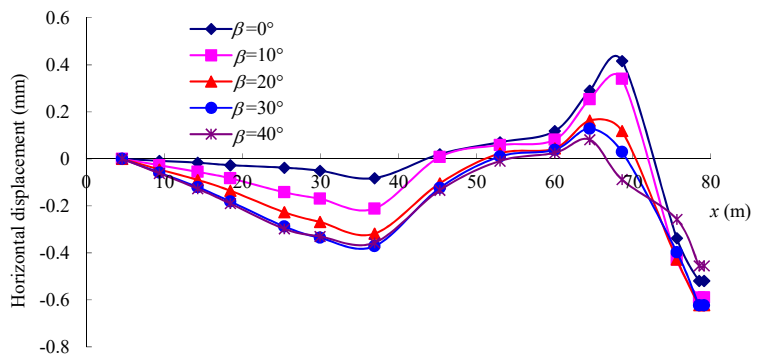

(b) Horizontal displacement

Fig. 6. Displacement of the surface at $\mathrm{z}=0$ plane

From the above analysis, it can be seen that in terms of the stability control of the head slope, $\beta$, the more stable the surrounding rock is. The tunnel axis is nearly parallel to the inclination of the front slope (i.e. entering the tunnel vertically on the slope, $\beta=0^{\circ}$ ). It is most suitable because it is mainly to control relatively large deformation and vertical displacement.

\section{Conclusions}

Due to the lack of enough attention to the influence of tunnel excavation on the stability of the front slope, failure occurred in the process of excavation in many projects. In this paper, numerical calculation was used to analyze the front slope deformation after tunnel excavation under different conditions. The conclusions can be generally summarized as:

(1) When the front slope angle $\alpha$ is $30^{\circ}$, The shear stress concentration area of surrounding rock appears at both sides of arch foot and shallow side arch. When $\alpha$ is greater than $40^{\circ}$, there is also a shear stress concentration area at the deep side arch waist, and the shear stress 
concentration area gradually expands with the increase of $\alpha$. The deformation of the tunnel may "transfer" to the side of the ridge, so the treatment of the slope on the side of the ridge should be paid more attention in the process of tunnel excavation.

(2) When $\alpha$ is less than $40^{\circ}$, the slope deformation caused by tunnel excavation is small. When $\alpha$ is greater than $40^{\circ}$, the slope deformation caused by tunnel excavation is larger with the increase of $\alpha$. In order to ensure the safety of construction, we should not only pay attention to the treatment of the front slope before the tunnel excavation, but also pay attention to the monitoring of the front slope deformation during the excavation of the tunnel portal section.

(3) The larger the angle $\beta$ is, the more serious the collapse near the tunnel is, and the scope of collapse moves to the side of the ridge. This may be due to the adjustment of the direction of the tunnel entering, which alleviates the topographic bias caused by the slope when the tunnel enters the straight and small angle oblique tunnels to a certain extent. Therefore, the best entry angle $\beta$ is $0^{\circ}$, which can control the vertical displacement of relatively large deformation.

(4) The numerical method was used to simulate the influence of tunnel excavation on slope in different cases. Model test can be used to further study the mechanism of slope affected by tunnel excavation.

\section{References}

1. WANG Junbao, LIU Xinrong, SONG Zhanping. Landscape design of mountain highway tunnel portals in China. Tunnelling and Underground Space Technology, 2012, (29): 52 - 68.

2. X. LI, P. ZHANG, Z. HE, Z. HUANG, M. CHENG, \& L. GUO. Identification of geological structure which induced heavy water and mud inrush in tunnel excavation: a case study on lingjiao tunnel. Tunnelling and Underground Space Technology, 2017, 69(10), 203-208.

3. C.N. SONG, Y. DENG, D.B. LIU, C.H. HE. Study on Seepage Characteristics and Excavation Stability of Loose Cohesive Slope of Earth Rock Cofferdam under Different Dewatering Speed of Foundation Pit. Water Resource and Power, 2021, 39(2): 69 - 73.

4. J. ZHANG, L.W. ZHANG. Deformation Characteristics and Prevention Analysis of a Deep and Thick Fill Slope. Geotechnical Engineering Technique, 2020, 34(6): 344 - 348.

5. K. QIN, Z. YANG. Numerical Analysis on Stress Redistributions in Surrounding Rock of Underground Caverns in Wudongde Hydropower Station, 2021, 47(4): 29 - 34.

6. A.P. CHEN, Y.J. YANG. Stability analysis and reinforcement measures of high and steep slope of Cheng-Lan Railway. Engineering Journal of Wuhan University, 2021, 54(6): 515 - 523.

7. Q.K. WANG, S.C. LIANG, X.L. SONG. Analysis of Typical Soil-rock Mixture Slope Stability with
Different Stone Contents. Journal of Water Resources and Architectural Engineering 2021, 19(2): $30-35$.

8. Y. ZHAO, D.Q. XU. Study on stability of shallow buried bias tunnel with different distance of tunnel faces. Journal of Hebei University of Technology, 2021, 50(1): $81-91$.

9. C. YANG. Y.X. ZAHNG, D. HUANG, Q. ZHU. Deformation behaviour of topographic unsymmetrical loaded tunnels and their prereinforcemets after excavation, Journal of Highway and Transportation Research and Development, 2013, 7(3): 69 - 75.

10. H. ZHANG. Study on Failure Mechanism and Reinforcement of Slope at Tunnel Entrance. Shandong Jianzhu University, 2019.

11. Q.H. WANG. Study on the deformation and treatment scheme of the front slope at the entrance of highway tunnel, 2015, 129(09): $202-205$. 